REVIEW

\title{
The dendritic cell: its role in intestinal inflammation and relationship with gut bacteria
}

\author{
A J Stagg, A L Hart, S C Knight, M A Kamm
}

Gut 2003;52:1522-1529

Dendritic cells are antigen presenting cells that are likely to be pivotal in the balance between tolerance and active immunity to commensal microorganisms that is fundamental to inflammatory conditions, including Crohn's disease and ulcerative colitis. Interactions between dendritic cells and microbial products are discussed and how they contribute to regulation of immune responses. The concept that interactions between dendritic cells and commensal organisms may be responsible for maintaining intestinal immune homeostasis is also explored.

See end of article for authors' affiliations

Correspondence to:

Dr A J Stagg, APRG,

Faculty of Medicine,

Imperial College London,

Northwick Park Campus,

Watford Rd, Harrow HÁl

3UJ, Middlesex, UK;

a.stagg@imperial.ac.uk

Accepted for publication 10 June 2003

\section{SUMMARY}

Dendritic cells (DC) are antigen presenting cells that act as sentinels, acquiring antigen and transporting it to lymphoid tissue where they have the unique ability to activate naïve $\mathrm{T}$ cells. From this pivotal position at the intersection of innate and adaptive immunity, DC shape many aspects of the developing immune response. They can determine whether non-responsiveness (tolerance) or an active immune response occurs, whether a type 1 or type 2 response predominates, and they may control tissue specific homing of antigen specific effector cells. Microbial products play a central role in modulating DC function and influencing these different immune outcomes. Using molecules including toll-like receptors, DC recognise and respond to microbe specific molecular structures. DC can distinguish between and initiate different responses to even closely related organisms. Emerging evidence suggests that intestinal DC are critical for regulation of immunity in the gut. They are likely to be pivotal in the balance between tolerance and active immunity to commensal microorganisms that is fundamental to inflammatory conditions, including Crohn's disease and ulcerative colitis. Here, we describe how interactions between DC and microbial products contribute to regulation of immune responses and explore the concept that interactions between DC and commensal organisms may be responsible for maintaining intestinal immune homeostasis.

\section{INTRODUCTION}

The balance between tolerance and an active immune response to antigens in the intestine is fundamental to the pathogenesis of inflammatory gastrointestinal conditions, including
Crohn's disease and ulcerative colitis. One of the immune cells central to this process, the "conductor of the immune orchestra", is the dendritic cell (DC) (fig 1). DC sample enteric antigens and present them to the immune system. They can control whether an immune response occurs to a particular antigen and shape the nature of any response. Modulation of dendritic cells by bacterial products influences these different outcomes and therefore interactions between dendritic cells and bacteria are central to the regulation of intestinal immunity.

In this review, we initially briefly discuss the immunobiology of DC, drawing mostly on work on cells from outside the gut, and then consider how DC are modulated by bacterial products. The focus then moves to the emerging information on intestinal DC and their importance for immunoregulation. Finally, we discuss the interaction between DC and the commensal microflora, to speculate how this interaction may be responsible for maintaining intestinal immune homeostasis.

\section{THE BIOLOGY OF DENDRITIC CELLS} What are dendritic cells?

DC are bone marrow derived antigen presenting cells. They are present in small numbers in most tissues but have a disproportionately large influence on immune responses. For example, one DC can influence the function of between 300 and 1000 T cells. For a detailed discourse on DC biology, the reader is referred to a number of recent reviews. ${ }^{1-5}$ DC have two major functions: acquisition of antigen and stimulation of lymphocytes. ${ }^{6}$ Usually antigen acquisition occurs in peripheral tissues by "immature" DC which are endocytically active cells expressing low levels of cell surface MHC class II and costimulatory molecules (for example, CD80, CD86, and CD40). These immature DC are weak stimulators of $\mathrm{T}$ cell proliferation. As illustrated in fig 2, most immature tissue DC are replenished from circulating blood precursors that arise in the bone marrow and may include monocytes as well as the blood DC population.

\footnotetext{
Abbreviations: DC, dendritic cell; IL, interleukin; TNF- $\alpha$, tumour necrosis factor $\alpha$; GM-CSF, granulocyte macrophage-colony stimulating factor; IFN, interferon; LPS, lipopolysaccharide; TLRs, Toll-like receptors; DCSIGN, DC specific intercellular adhesion molecule 3 grabbing non-integrin; ICAM, intercellular adhesion molecule; TGF- $\beta$, transforming growth factor $\beta$; IBD, inflammatory bowel disease
} 


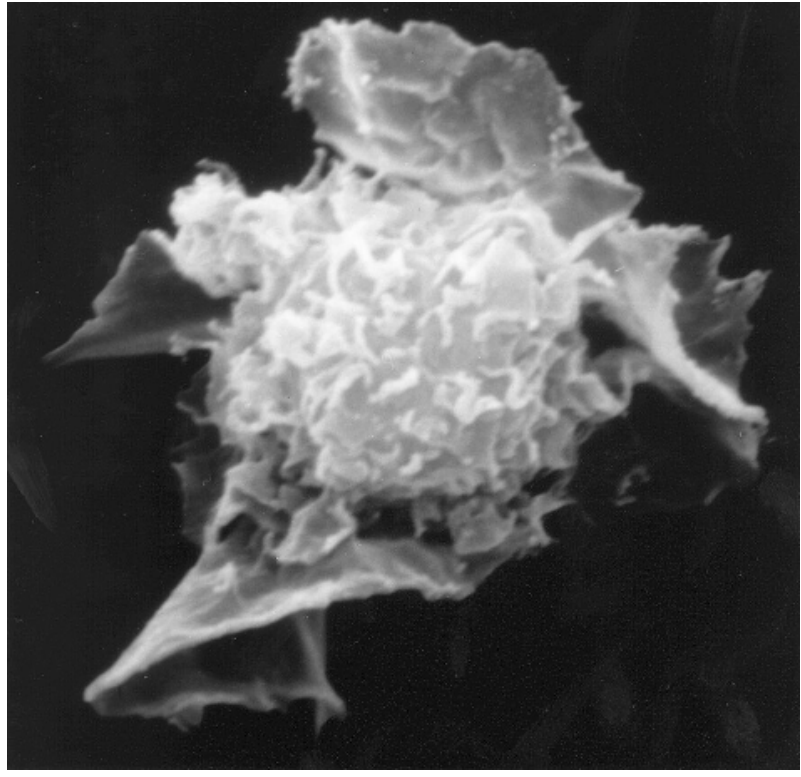

Figure 1 Scanning electron micrograph of a human dendritic cell (from the work of Brigid Balfour, courtesy of Nick English).

DC undergo maturation and migrate to draining lymph nodes in response to signals that indicate local "danger" or tissue damage. These signals include microbial products and/or cytokines such as tumour necrosis factor $\alpha$ (TNF- $\alpha$ ). During maturation, DC upregulate their expression of MHC class II and costimulatory molecules and acquire the ability to stimulate naïve $\mathrm{T}$ cells. Communication between DC and $\mathrm{T}$ cells is a two way process with important interactions occurring particularly between members of the TNF and TNF receptor protein families. ${ }^{78}$ These interactions serve to further activate the DC and regulate their survival.

\section{Control of immune responses by DC}

Both the maturational state and type of DC influence the subsequent $\mathrm{T}$ cell response. Immature or partially mature DC that traffic from peripheral to lymphoid tissue presenting self antigens ${ }^{9}$ inhibit potentially autoreactive $\mathrm{T}$ cells that have escaped thymic deletion. ${ }^{10}{ }^{11}$ Non-responsiveness is not confined to self antigens but can also be induced to foreign antigens if they are delivered in a way that avoids activation of DC. ${ }^{12}$

In contrast, "mature" DC can activate and drive clonal expansion of proliferative $\mathrm{T}$ cells. They also shape the functional differentiation of these dividing T cells. DC derived signals are a major influence on the generation of polarised Th1 and Th2 responses. ${ }^{4}$ DC can produce interleukin (IL)-12, IL-18, and IL-23 contributing to a Thl response. ${ }^{13}$ They can produce IL-4(Kelleher and colleagues ${ }^{14}$ and Maroof, personal communication) or IL- $10,{ }^{15}$ contributing to a Th2 response or the generation of regulatory $\mathrm{T}$ cells. Some activated DC induce regulatory $\mathrm{T}$ cells or tolerance $\mathrm{e}^{16}{ }^{17}$ and may act to limit an established immune response in order to minimise inflammatory collateral damage.

DC can be divided into subsets that differ with regard to phenotype, function, and anatomical location. ${ }^{351819}$ These subsets may have predetermined functions or display plasticity, depending on their local environment.

Two major DC populations are present in human peripheral blood. CDllc+ DC are termed DCl or myeloid DC. They express high levels of the granulocyte macrophage-colony stimulating factor (GM-CSF) receptor but low levels of the IL-3 receptor (CD123). In contrast, CDl1c- DC are called plasmacytoid or lymphoid DC. They express high levels of CD123 but little GM-CSF receptor and require activation before displaying characteristic stimulatory activity in vitro. They are sometimes called precursors of DC2 (pDC2) because

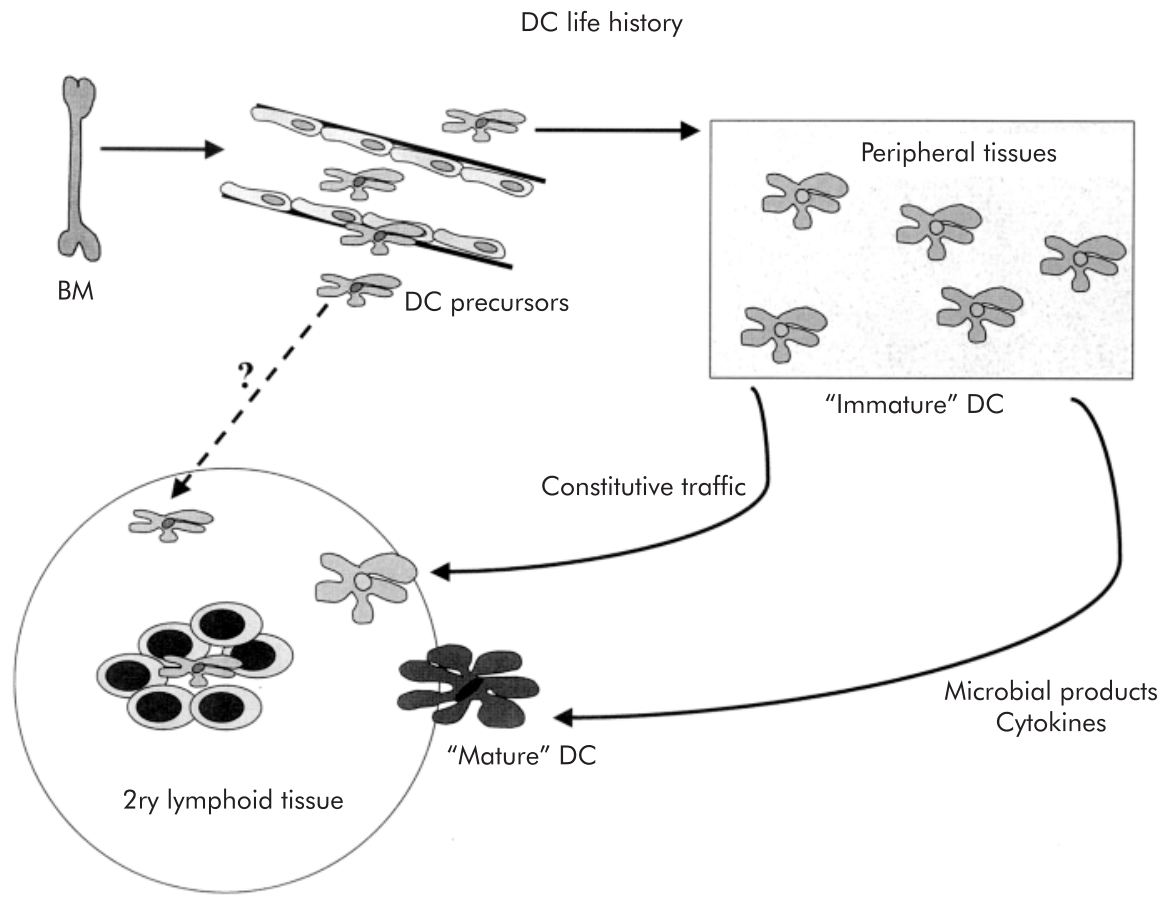

Figure 2 The life history of dendritic cells (DC). DC precursors derived from the bone marrow (BM) migrate via peripheral blood to lymphoid tissue or non-lymphoid tissue where they briefly reside as "immature" cells capable of efficient antigen uptake but expressing low levels of costimulatory molecules. In response to cytokines and microbial products, these DC migrate to draining lymph nodes and mature into highly immunostimulatory cells. Some DC constitutively migrate as non-activated or partially activated cells and these DC may play a role in tolerance. 
of their relative immaturity. In contrast, in the mouse there are three major DC populations, all of which are CDllc+: myeloid, plasmacytoid, and "lymphoid" DC populations. The lymphoid population, for which there is currently no human equivalent, is characterised by expression of a homodimer of the $\operatorname{CD} 8 \alpha$ molecule. The relationship between these CD $8 \alpha \alpha+$ "lymphoid" DC and other mouse DC populations remains controversial $^{20}$ but progenitors have been identified that can give rise to all subtypes of DC. ${ }^{19} 21-23$

"Many studies have linked DC subsets with particular functions, such as Th1/Th2 differentiation or tolerance induction"

Many studies have linked DC subsets with particular functions, such as Th1/Th2 differentiation or tolerance induction. For instance, production of large amounts of type 1 interferons $(\mathrm{IFN}-\alpha / \beta)$ in response to viral antigens is characteristic of plasmacytoid DC in both humans and mice. ${ }^{24-26}$. In general, murine CD $8 \alpha \alpha+$ DC and human myeloid DC are associated with elevated IL-12 production and the generation of IFN- $\gamma$ producing Thl cells. ${ }^{27}{ }^{28}$ However, the concept of DC subtypes producing fixed patterns of response is probably an oversimplification. Indeed, myeloid DC from mice have been reported to favour the generation of either Th1 or Th2 responses. ${ }^{28-30}$ Human CD1lc- plasmacytoid DC can produce IFN- $\alpha$ leading to the generation of IFN- $\gamma$ producing $\mathrm{T}$ cells, but can also generate Th2 responses. ${ }^{27} \mathrm{~A}$ role for murine plasmacytoid DC in generating Thl responses is indicated by their ability to make IL- $12 .{ }^{26}$ It is likely that the profile of DC cytokine production is not fixed but regulated by environmental signals, including microbial products. $^{31}$

\section{MODULATION OF DENDRITIC CELL FUNCTION BY MICROBIAL PRODUCTS}

Microbial products such as lipopolysaccharide (LPS) stimulate DC maturation. However, the full complexity of the interaction between DC and microbes is only now being recognised. Exposure of DC, grown from mouse bone marrow, to an antigen from the nematode Acanthocheilonema viteae promoted the generation of a Th2 response whereas exposure to LPS favoured a Thl response. ${ }^{32}$ In human studies using monocyte derived DC, an extract from the heliminth Schistosoma mansoni, or to a bacterial toxin from Vibrio cholerae, favoured Th2 responses, whereas Bordella pertussis toxin or the viral mimic poly(I:C) generated Thl responses. ${ }^{33}$

As illustrated in fig 3, DC can distinguish between closely related microbial structures or organisms. LPS from Escherichia coli stimulated IL-12 production and generated a Thl response in mice whereas LPS from Porphyromonas gingivalis did not stimulate IL-12 production and generated a Th2 response. ${ }^{34}$ Murine DC lines produced IL- 12 and primed Thl responses when they ingested Candida albicans as a unicellular yeast whereas IL-4 was produced, IL-12 inhibited, and Thl priming downregulated when the hyphal form of the fungus was ingested. ${ }^{35}$ A single amino acid change appears sufficient to account for the ability of a Theiler's virus variant to stimulate IL-10 production from mouse spleen DC rather than the production of IL-12 observed with the wild-type virus. ${ }^{36}$

\section{"By responding differentially to different types of microbes, DC can signal the nature of the pathogen"}

Oligonucleotide microarrays have been used to compare gene expression profiles of human monocyte derived DC
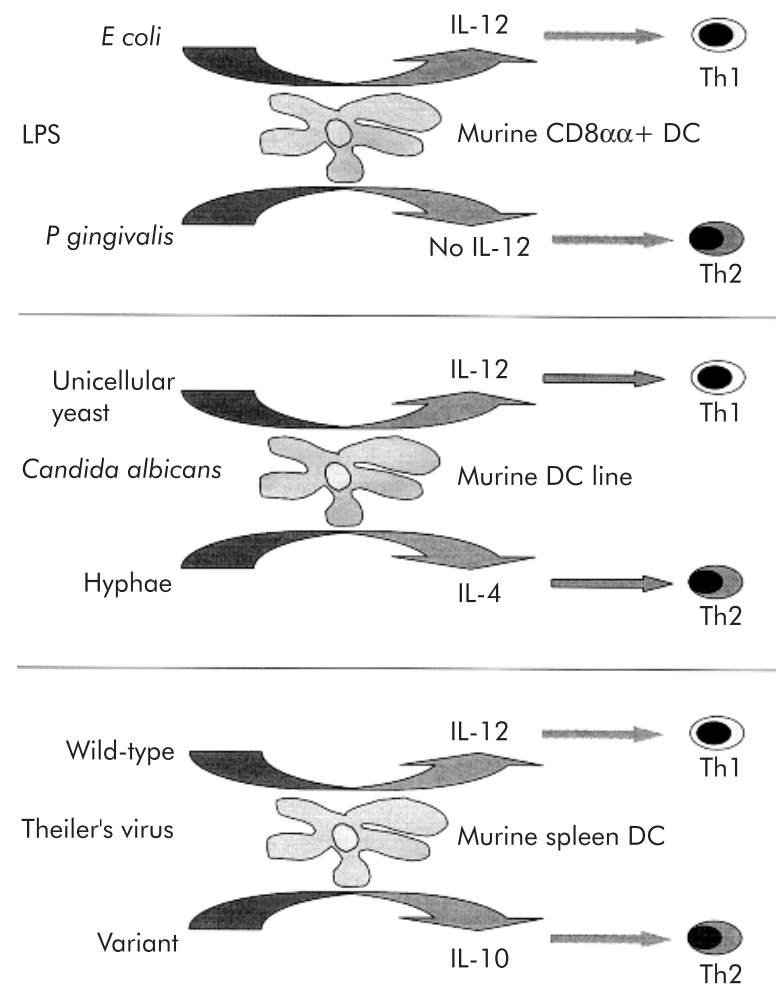

Figure 3 Closely related organisms or microbial products can stimulate dendritic cells (DC) to make different cytokines and as a consequence can shape a developing T cell response. IL, interleukin; LPS, lipopolysaccharide. (See text for details.)

exposed to Candida, influenza virus, or $E$ coli (or components thereof). ${ }^{37}$ Of approximately 6800 genes on an array, 1330 were altered in expression in the presence of at least one of the stimuli. Some response occurred to all antigens but others were stimulus specific. By responding differentially to different types of microbes, DC can signal the nature of the pathogen. ${ }^{31}$ This type of study demonstrates the principle that DC can discriminate between microbes. However, monocyte derived DC may not be representative of all DC populations and microarray analysis has yet to be performed on DC from the intestine. Gut DC may interact with microbial products in a distinct manner (see below).

\section{How do DC sense their microbial environment?}

DC express a series of promiscuous surface receptors (pattern recognition receptors) that recognise common structural elements of microorganisms. Cell wall components such as LPS or peptidogycan, umethylated CpG motifs in bacterial DNA, or double stranded viral RNA are recognised by Tolllike receptors (TLRs) which take their name from the structurally related Drosophila receptor called Toll. Ten members of the TLR family have currently been reported and for some the microbial product recognised has been reported..$^{38}$ TLR4 is required for recognition of LPS from $E$ coli, TLR2 is required for recognition of Gram positive cell wall components including peptidoglycan and certain lipoproteins $^{39}$ and LPS from Porphyromonas gingivalis, TLR5 recognises flagellin from Gram negative bacteria, and TLR9 recognises GpG motifs from bacterial DNA. TLR4 is essential for both maturation and cytokine production in LPS stimulated murine DC. ${ }^{40}$ Signalling through different TLRs generates distinct biological responses and differential expression of TLR by different subsets of DC ${ }^{41-44}$ may allow DC subsets to 
respond to particular microbial structures in a specific manner.

DC also express several C-type lectin receptors. ${ }^{45}$ The best characterised of the C-type lectins is DC-SIGN (DC specific intercellular adhesion molecule 3 grabbing non-integrin). DC-SIGN interacts with intercellular adhesion molecule (ICAM)-2 on vascular endothelium to promote extravasation of immature DC ${ }^{46}$ and with ICAM-3 on T cells to stabilise the immunological synapse and enhance T cell activation. ${ }^{47} \mathrm{DC}$ SIGN also binds a number of micobial products. ${ }^{48-51}$ Binding of the mycobacterial cell wall component lipoarabinomannan to DC-SIGN inhibits DC maturation in response to other microbial signals, possibly by interfering with TLR signalling. ${ }^{50}$ Therefore, the functional activity of a DC population in a given anatomical site may depend on the balance of conflicting microbial signals as well as other environmental signals.

\section{DENDRITIC CELLS IN THE INTESTINE}

The specialised immune system of the gut needs to respond appropriately to the large antigenic load normally present in the form of food antigens and commensal bacteria as well as to occasional pathogenic organisms. DC are likely to be central to this process. They are present in organised lymphoid tissue associated with the intestine-that is, Peyer's patches, mesenteric lymph nodes, and the more recently described cryptopatches and isolated lymphoid follicles/lymphocyte filled villi. ${ }^{52-54}$ DC are also present in the lamina propria and possibly in the epithelium. ${ }^{3055}$ Reflecting the specialised environment of the intestine, gut DC have distinct properties and functions. ${ }^{15}$ 56-58

\section{"The population of gut DC is a dynamic one, with cells constantly trafficking into and out of the gut compartment"}

The population of gut DC is a dynamic one, with cells constantly trafficking into and out of the gut compartment. In the steady state, DC transit through the gut with a turnover time of a few days. ${ }^{59}$ This is comparable with estimates for survival at other mucosal sites but is considerably more rapid than the turnover of Langerhans' cells in the skin. ${ }^{6061}$ Migration of gut DC can be further increased by inflammatory stimuli, including TNF- $\alpha .{ }^{62}$ Our recent studies on DC in the murine colon have demonstrated the presence of both CDllb+ and CDllb- DC subpopulations but no CD $8 \alpha+$ DC. In the human colon, lamina propria DC are largely CDllct "myeloid" cells ${ }^{63}$ with few identifiable plasmacytoid (CD1lc-CD123 hi $)$ DC. However, these CDllc+ human colonic DC are themselves heterogeneous. The functional significance of this variation in DC subsets is currently under investigation.

\section{Sampling of luminal contents by dendritic cells}

Intestinal DC are in close apposition with the gut contents and can sample antigens from the intestinal lumen (fig 4). ${ }^{64} 65$ Traditionally, much emphasis has been placed on sampling via $M$ cells of the follicle associated epithelium in the Peyer's patch of the small intestine but additional routes of antigen sampling are also likely to be involved. Firstly, DC in the lamina propria may open tight junctions between epithelial cells sending processes into the lumen to sample antigen directly. ${ }^{66}$ Expression of tight junction proteins by DC themselves preserves the integrity of the intestinal barrier. Secondly, DC may acquire antigen indirectly. DC internalise apoptotic epithelial cells ${ }^{57}$ or may take up antigen bearing exosomes shed from epithelial cells. ${ }^{67}{ }^{68}$ Thirdly, antigenic material interacts directly with DC in underlying tissue. This may occur particularly when epithelial integrity is compromised.

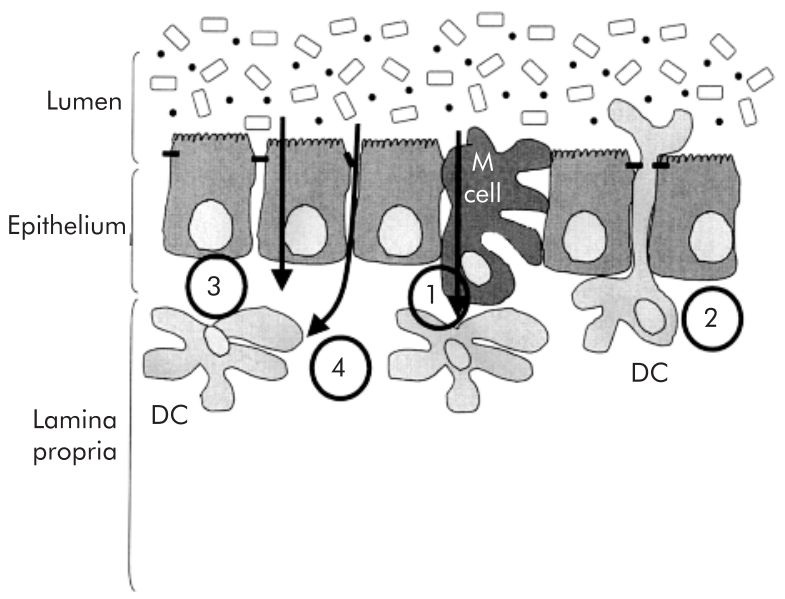

Figure 4 Sampling by dendritic cells (DC) of antigens in the intestinal lumen. At least four pathways have been described by which $D C$ can acquire gut antigens: (1) following transport of antigens by $M$ cells; (2) by reaching between epithelial cells directly into the lumen; (3) via the epithelium, either by uptake of material transported by epithelial cells or following uptake of apoptotic epithelial cells; and (4) by direct access to antigens as a result of breaks in the integrity of the epithelium.

\section{Control of intestinal immune responses by dendritic cells}

In laboratory mice, the intestinal mucosa is particularly conducive to induction of helper T cells producing type 2 (IL4 , IL-5, and IL-10) and type 3 (transforming growth factor $\beta$ $($ TGF- $\beta)$ ) cytokines. This pattern of cytokine production creates an environment that favours the production of IgA and $\mathrm{T}$ cell non-responsiveness to fed antigens (oral tolerance), two characteristic features of immunity in the gut. In turn, the pattern of $\mathrm{T}$ cell cytokine production is probably controlled by signals from the activating gut DC. Murine Peyer's patch DC upregulate IL-10 rather than IL-12p40 ${ }^{15} 69$ and generate $\mathrm{T}$ cells that produce high levels of IL-4 and IL-10 and less IFN- $\gamma$. In contrast, DC from the spleen produce IL12p40, but little IL-10, and generate $\mathrm{T}$ cells producing predominately IFN $-\gamma .{ }^{15}$ Gut DC may also have the ability to make TGF- $\beta{ }^{15} 5870$

It is currently unclear whether the immune environment in the human intestine is the same as that in the laboratory mouse. In the human gut, responses may be biased towards a type 1 profile rather than a type 2 pattern, ${ }^{71}$ possibly as a result of differences in the commensal microflora between the two species. ${ }^{72}$ Ways in which interactions between DC and bacteria may differ between mice and men remain to be explored.

\section{"DC are involved in the generation of oral tolerance in mice"}

DC are involved in the generation of oral tolerance in mice. Treatment with the growth factor Flt3L, which increases DC numbers in the gut associated lymphoid tissue, reduces the concentration of antigen required to oral tolerance. ${ }^{73}$ The expanded DC population is of a resting or "immature" phenotype. This immature state is critical for enhanced oral tolerance because coadministration of IL- $1 \alpha$, as a DC activating stimulus, converts a tolerogenic response into an active one. ${ }^{74}$

Gut DC may also be able to influence migration and tissue specific homing of the lympocytes that they activate. Lymphocytes that have been activated in lymphoid tissue have a propensity to home back selectively to the gut and to 
other mucosal sites. ${ }^{75}$ Interactions between the addressin MAdCAM-1 on endothelial cells and the integrin $\alpha 4 \beta 7$ on lymphocytes contribute to entry of these lymphocytes into intestinal tissue. ${ }^{76}{ }^{77}$ We have observed that threefold more $\mathrm{T}$ cells express high levels of $\alpha 4 \beta 7$ if they are activated in vitro by mouse DC from mesenteric lymph nodes than if they are activated by DC from peripheral lymph nodes. ${ }^{58}$ Thus gut DC may target $\mathrm{T}$ cells back to intestinal tissue (fig 5 ).

Accumulating evidence that gut DC have distinct functional properties raise questions about whether these properties are determined by effects on DC of the local microenvironment or whether there may be functionally committed DC precursors that home selectively to intestinal tissue (fig 6). Locally acting factors may include cytokines, arachidonic acid metabolites, or direct action of microbial products in the gut lumen. Blood precursors of skin Langerhans' cells have a distinct phenotype ${ }^{78} 79$ providing a precedent for the concept of tissue specific precursors.

The $\beta 7$ integrins may be important in the migration of committed DC precursors into the gut (fig 6). DC precursors in human peripheral blood are heterogeneous in their level of expression of $\alpha 4 \beta 7 .^{80} \alpha 4 \beta 7$ may therefore contribute to a generalised mechanism of cell entry into intestinal tissue and provide a mechanism to direct subpopulations of DC precursor to the gut.

\section{ALTERATION OF DENDRITIC CELLS IN INFLAMMATORY BOWEL DISEASES}

Given that the inflammatory bowel diseases (IBD) are related to dysregulated immune responses to intestinal flora, an examination of the role of the DC as a central mediator demands investigation. It is now possible to extract sufficient numbers of DC from the human gut to perform phenotypic and functional studies. ${ }^{63}$

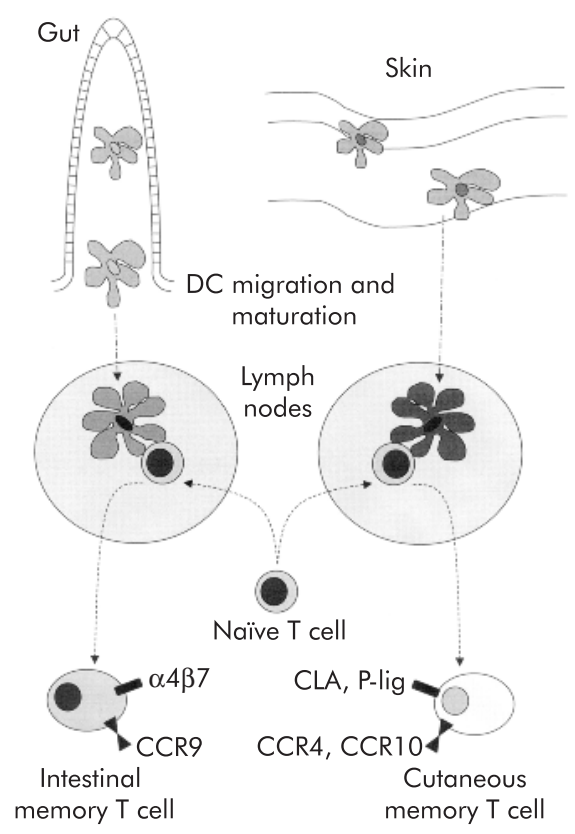

Figure 5 Control of tissue specific lymphocyte homing by dendritic cells (DC). DC draining from the intestine, but not the skin, can induce expression of the mucosal homing integrin $\alpha 4 \beta 7$ on naive T cells that they activate. In conjunction with the possible induction of other molecules associated with homing to the intestine (for example, CCR9) this expression may allow DC to target effector cells efficiently to the site of intestinal antigenic challenge. By analogy, molecules associated with lymphocyte homing to the skin (for example, CLA, P-selectin ligand, CCR4, or CCR 10) may be induced by skin draining DC. ${ }^{102}$
"DC from inflamed Crohn's disease lamina propria express higher levels of CD40 than DC from non-inflamed Crohn's disease or from healthy control tissue ${ }^{\prime \prime}$

DC from inflamed Crohn's disease lamina propria express higher levels of CD40 than DC from non-inflamed Crohn's disease or from healthy control tissue. ${ }^{81}$ Elevated levels of CD40 returned to normal following treatment with anti-TNF- $\alpha$. These findings on isolated cells are consistent with immunohistological studies showing increased numbers of DC expressing CD40, CD86, ${ }^{82} \mathrm{CD}^{83}{ }^{83}{ }^{84}$ and $\mathrm{CD}^{84} 0^{84}$ in mucosal tissue from Crohn's disease and ulcerative colitis patients. CD40 is thought to play an important role in DC activation and inflammation; signalling via CD40 causes DC IL-12 production, upregulation of CD134L (OX40L), increased DC maturation, and enhanced DC survival. The ligand for CD40 is also upregulated in the mucosa of IBD patients. $^{85}$

A number of other studies in human IBD have identified changes in myeloid-type antigen presenting cells that probably include DC..$^{86-90}$ However, the markers used to identify cells did not always permit DC and monocyte/ macrophage populations to be fully discriminated. These issues will be clarified by detailed functional analysis of separated cells in conjunction with histological studies. Currently, comparison of immunohistological analysis of DC with studies on isolated cells is made difficult by the use of different markers to identify the cells in the two experimental settings.

Colonic lamina propria DC also show evidence of activation in murine models of colitis ${ }^{91}$ and recent experiments suggest that DC play an early and fundamental role in disease. In immune deficient mice, DC aggregates were identified under the basal crypt epithelium at the mucosa/submucosa junction. When pathogenic $\mathrm{T}$ cells were transferred to these mice they clustered and proliferated in these aggregates 5-10 days before overt colitis could be detected, suggesting that the DC were involved in the initial activation or restimulation of pathogenic T cells. ${ }^{92}$ In a model in which colitis was induced by transfer of CD45RB ${ }^{\text {hi }} \mathrm{T}$ cells into immune deficient mice, there was a 15-36-fold increase in the number of activated (CD134L+) DC in the mesenteric lymph nodes. ${ }^{93}$ Antibody to CD134L blocked development of colitis, supporting an important role for CD134L+ DC. DC accumulating in the colon of these colitic mice were not CD134L+, implicating the mesenteric nodes as the likely site of interaction between CD134+ T cells and CD134L+DC. Although these two studies place a different emphasis on the location of $\mathrm{T}$ cell-DC interaction, they both support a central role for this interaction in the development of disease.

\section{INTERACTION OF GUT DENDRITIC CELLS WITH COMMENSAL BACTERIA}

The preceding sections have provided evidence for the central role of DC in immunoregulation, the specialised functions of gut DC, and the crucial ways in which bacteria modulate DC function. It remains to be determined how gut DC are influenced by the intestinal bacterial flora and whether coexistence with this large number of bacteria requires functional adaptation on the part of intestinal DC. DC are present in the GALT of germ free animals ${ }^{57}$ but detailed functional analysis of these DC populations has not been performed.

Sampling of luminal contents will expose DC to potentially activating microbial products. DC bearing antigens from intestinal bacteria are present in MLN but not other nodes or spleen of normal mice ${ }^{94}$ and this could result from constitutive sampling of the flora. Specific $\operatorname{IgA}^{95}$ and $\mathrm{T}$ cell responses ${ }^{96}$ indicate immune recognition of antigens from the 


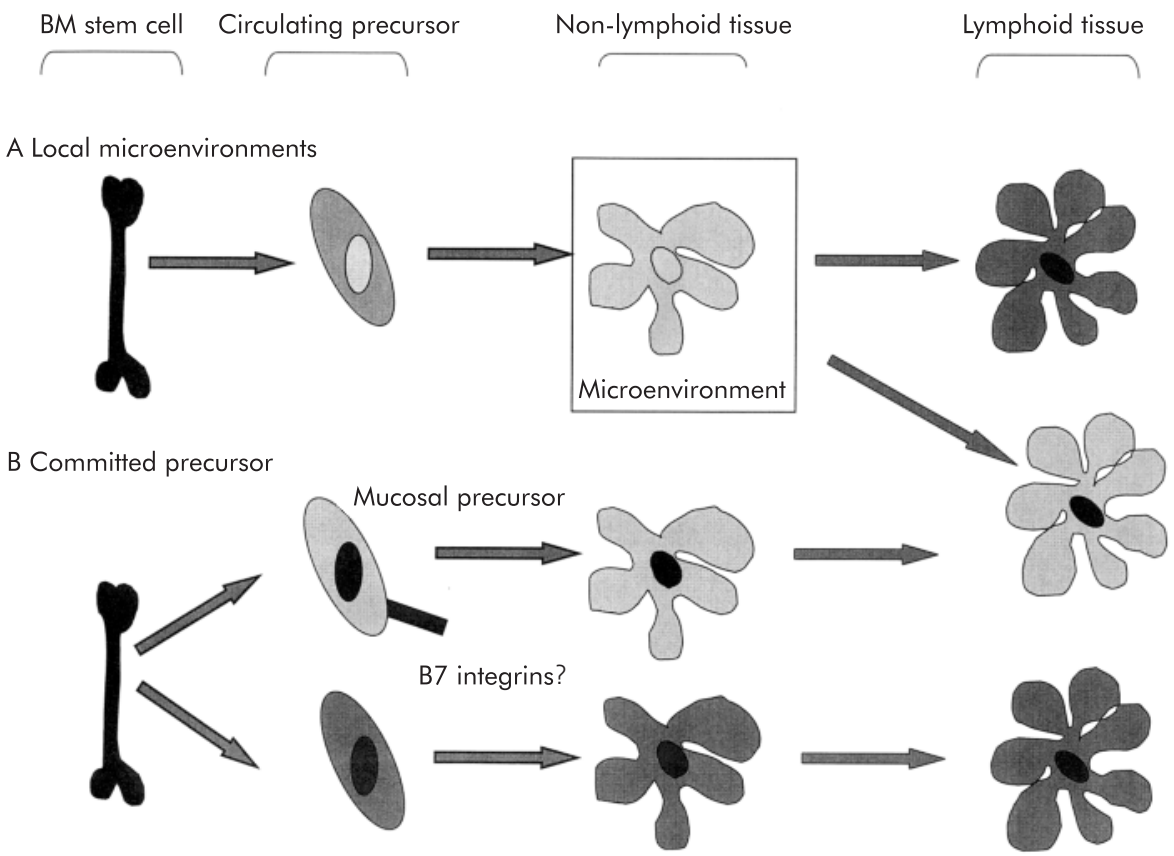

Figure 6 The origin of tissue specific dendritic cell functions. Gut dendritic cells (DC) (illustrated in light grey) and non-intestinal DC (dark grey) have tissue specific functions. These might result from the action of local microenvironmental factors on a common precursor (A) or from migration of distinct functionally committed precursors (B) or a combination of both mechanisms. The integrin $\beta 7$ is expressed by some human DC precursors and may contribute to homing of some DC to the gut. BM, bone marrow.

flora. Moreover, translocation or penetration of intestinal bacteria into the underlying tissue does occur, ${ }^{97}$ making them available to DC deeper in the tissues. Translocation does not normally harm the host because the organisms are removed by phagocytic cells; abdominal abscesses containing enteric commensals develop in mice whose phagocytic killing is severely impaired..$^{98}$

Gut DC may regulate responses to the normal flora in a way that is analogous to the induction of tolerance to self antigens by other immature DC populations. But how would immature gut DC avoid becoming activated by gut bacteria, a state that would be predicted to result in active immunity rather than non-responsiveness? This area requires much further study but work from our unit has shown that colonic DC can produce both IL-12 and IL-10 when cultured with bacteria. ${ }^{99}$ The predominant cytokine depends on the nature of the stimulus: cell walls from Bifidobacterium longum stimulate predominately IL-10 production whereas LPS stimulates production of IL-12 but little IL-10. This differential modulation of DC by microbial products suggests that treatment with probiotic bacteria may function in part by modulating the function of gut DC. ${ }^{58} 100101$

\section{CONCLUSIONS}

Two aspects of gut immune regulation are now well established: (i) the intestinal microflora plays a critical role in the maintenance of health and disease in the gut; and (ii) DC play a central role in regulating immunity. The recognition that DC function is highly plastic and regulated by microbial products provides a potential link between these two sets of findings. Understanding the interaction between specialised populations of gut DC and the commensal flora may prove a key to understanding immune regulation in the gut and open the way for new therapeutic approaches for inflammatory bowel diseases.

\section{ACKNOWLEDGEMENTS}

Grant support for the study was provided by the Medical Research Council and the Wellcome Trust

\section{Authors' affiliations}

A J Stagg, A L Hart, S C Knight, Antigen Presentation Research Group, Faculty of Medicine, Imperial College London, UK

M A Kamm, St Mark's Hospital, Harrow, UK

\section{REFERENCES}

1 Banchereau J, Briere F, Caux C, et al. Immunobiology of dendritic cells. Annu Rev Immunol 2000;18:767-811.

2 Heath WR, Carbone FR. Cross-presentation, dendritic cells, tolerance and immunity. Annu Rev Immunol 2001 ; 19:47-64.

3 Liu YJ. Dendritic cell subsets and lineages, and their functions in innate and adaptive immunity. Cell 2001;106:259-62.

4 Moser M, Murphy KM. Dendritic cell regulation of TH1-TH2 development. Nat Immunol 2000;1:199-205.

5 Shortman K, Liu YJ. Mouse and human dendritic cell subtypes. Nature Rev Immunol 2002;2:151-61.

6 Banchereau J, Steinman RM. Dendritic cells and the control of immunity. Nature 1998:392:245-52.

7 Grewal IS, Flavell RA. CD40 and CD154 in cell-mediated immunity. Annu Rev Immunol 2000;16:111-35.

8 Theill LE, Boyle WJ, Penninger JM. RANK-L and RANK: T cells, bone loss, and mammalian evolution. Annu Rev Immunol 2002;20:795-823.

9 Scheinecker C, McHugh R, Shevach EM, et al. Constitutive presentation of a natural tissue autoantigen exclusively by dendritic cells in the draining lymph node. J Exp Med 2002:196:1079-90.

10 Lutz M, Schuler G. Immature, semi-mature and fully mature dendritic cells: which signals induce tolerance or immunity? Trends Immunol 2002;23:445

11 Steinman RM, Nussenzweig MC. Avoiding horror autotoxicus: the importance of dendritic cells in peripheral T cell tolerance. Proc Natl Acad Sci U S A 2002;99:351-8.

12 Hawiger D, Inaba K, Dorsett Y, et al. Dendritic cells induce peripheral T cell unresponsiveness under steady state conditions in vivo. J Exp Med 2001; 194:769-79.

13 Macatonia SE, Hosken NA, Litton M, et al. Dendritic cells produce IL-12 and direct the development of Th1 cells from naive $\mathrm{CD} 4^{+}$cells. J Immunol 1995; 154:5071-9. 
14 Kelleher P, Maroof A, Knight SC. Retrovirally induced switch from production of IL-12 to IL-4 in dendritic cells. Eur J Immunol 1999;29:2309-18.

15 Iwasaki A, Kelsall BL. Freshly isolated Peyer's patch, but not spleen, dendritic cells produce interleukin 10 and induce the differentiation of T helper type 2 cells. J Exp Med 1999;190:229-39.

16 Gilliet M, Liu YJ. Generation of human CD8 T regulatory cells by CD40 ligand-activated plasmacytoid dendritic cells. J Exp Med 2002:195:695-704.

17 Albert ML, Jegathesan M, Darnell RB. Dendritic cell maturation is required for the cross-tolerization of CD8+ T cells. Nat Immunol 2001;2:1010-17.

18 Reid SD, Penna G, Adorini L. The control of T cell responses by dendritic cell subsets. Curr Opin Immunol 2000;12:114-21.

19 Ardavin C, Martinez DH, Martin P, et al. Origin and differentiation of dendritic cells. Trends Immunol 2001;22:691-700.

20 Merad M, Fong L, Bogenberger J, et al. Differentiation of myeloid dendritic cells into CD8alpha-positive dendritic cells in vivo. Blood 2000;96:1865-72.

21 Traver D, Akashi K, Manz M, et al. Development of CD8alpha-positive dendritic cells from a common myeloid progenitor. Science 2000;290:2152-4.

22 Manz MG, Traver D, Miyamoto T, et al. Dendritic cell potentials of early lymphoid and myeloid progenitors. Blood 2001;97:3333-41.

23 del Hoyo GM, Martin P, Vargas HH, et al. Characterization of a common precursor population for dendritic cells. Nature 2002;415:1043-7.

24 Siegal FP, Kadowaki N, Shodell M, et al. The nature of the principal type 1 interferon-producing cells in human blood. Science 1999;284:1835-7.

25 Nakano H, Yanagita M, Gunn MD. CD1 lc(+)B22O(+)Gr-1(+) cells in mouse lymph nodes and spleen display characteristics of plasmacytoid dendritic cells. J Exp Med 2001;194:1171-8.

26 Asselin-Paturel C, Boonstra A, Dalod M, et al. Mouse type I IFN-producing cells are immature APCs with plasmacytoid morphology. Nat Immunol 2001;2:1144-50.

27 Rissoan M-C, Soumelis V, Kadowaki N, et al. Reciprocal control of T helper cell and dendritic cell differentiation. Science 1999:283:1183-6.

28 Pulendran B, Smith JL, Caspary G, et al. Distinct dendritic cell subsets differentially regulate the class of immune response in vivo. Proc Natl Acad Sci U S A 1999:96:1036-41.

29 Maldonado L, De Smedt T, Michel P, et al. CD8alpha+ and CD8alphasubclasses of dendritic cells direct the development of distinct $T$ helper cells in vivo. J Exp Med 1999;189:587-92.

30 Iwasaki A, Kelsall BL. Unique functions of $\mathrm{cd} 11 \mathrm{~b}(+)$, cd8alpha(+), and double-negative Peyer's patch dendritic cells. J Immunol 2001;166:4884-90

31 Vieira PL, de Jong EC, Wierenga EA, et al. Development of Th1-inducing capacity in myeloid dendritic cells requires environmental instruction. $J$ Immunol 2000; 164:4507-12.

32 Whelan $M$, Harnett MM, Houston KM, et al. A filarial nematode-secreted product signals dendritic cells to acquire a phenotype that drives development of Th2 cells. J Immunol 2000;164:6453-60.

33 de Jong EC, Vieira PL, Kalinski P, et al. Microbial compounds selectively induce Th1 cell-promoting or Th2 cell- promoting dendritic cells in vitro with diverse Th cell-polarizing signals. J Immunol 2002;168:1704-9.

34 Pulendran B, Kumar P, Cutler CW, et al. Lipopolysaccharides from distinct pathogens induce different classes of immune responses in vivo. J Immunol $2001 ; 167: 5067-76$

35 d'Ostiani CF, Del Sero G, Bacci A, et al. Dendritic cells discriminate between yeasts and hyphae of the fungus Candida albicans. Implications for initiation of T helper cell immunity in vitro and in vivo. J Exp Med 2000;191:1661-74.

36 Palma JP, Yauch RL, Kang HK, et al. Preferential induction of IL-10 in APC correlates with a switch from Th1 to Th2 response following infection with a low pathogenic variant of Theiler's virus. J Immunol 2002;168:4221-30.

37 Huang $Q$, Liu d, Majewski $P$, et al. The plasticity of dendritic cell responses to pathogens and their components. Science $2001 ; 294: 870-5$.

38 Akira S, Takeda K, Kaisho T. Toll-like receptors: critical proteins linking innate and acquired immunity. Nat Immunol 2001;2:675-80.

39 Takeuchi O, Hoshino K, Kawai T, et al. Differential roles of TLR2 and TLR4 in recognition of gram-negative and gram-positive bacterial cell wall components. Immunity 1999;11:443-51.

40 Kaisho T, Takeuchi O, Kawai T, et al. Endotoxin-induced maturation of MyD88-deficient dendritic cells. J Immunol 2001;166:5688-94.

41 Kadowaki N, Ho S, Antonenko S, et al. Subsets of human dendritic cell precursors express different toll-like receptors and respond to different microbial antigens. J Exp Med 2001;194:863-9.

42 Jarrossay D, Napolitani G, Colonna $M$, et al. Specialization and complementarity in microbial molecule recognition by human myeloid and plasmacytoid dendritic cells. Eur J Immunol 2001;31:3388-93.

43 Krug A, Towarowski A, Britsch S, et al. Toll-like receptor expression reveals CPG DNA as a unique microbial stimulus for plasmacytoid dendritic cells which synergizes with CD40 ligand to induce high amounts of IL-12. Eur J Immunol 2001;31:3026-37.

44 Baver M, Redecke V, Ellwart JW, et al. Bacterial CpG-DNA triggers activation and maturation of human CDI 1c-, CD123+ dendritic cells $J$ Immunol 2001; 166:5000-7.

45 Figdor CG, van Kooyk Y, Adema GJ. C-type lectin receptors on dendritic cells and Langerhans cells. Nature Rev Immunol 2002;2:77-84.

46 Geijtenbeek TB, Krooshoop DJ, Bleijs DA, et al. DC-SIGN-ICAM-2 interaction mediates dendritic cell trafficking. Nat Immunol 2000;1:353-7.

47 Geijtenbeek TB, Torensma R, van Vliet SJ, et al. Identification of DC-SIGN, a novel dendritic cell-specific ICAM-3 receptor that supports primary immune responses. Cell 2000;100:575-85.
48 Geijtenbeek TB, Kwon DS, Torensma R, et al. DC-SIGN, a dendritic cellspecific HIV-1-binding protein that enhances trans-infection of T cells. Cell 2000; 100:587-97.

49 Jameson B, Baribaud F, Pohlmann S, et al. Expression of DC-SIGN by dendritic cells of intestinal and genital mucosae in humans and rhesus macaques. J Virol 2002;76:1866-75.

50 Geijtenbeek TB, van Vliet SJ, Koppel EA, et al. Mycobacteria Target DCSIGN to suppress dendritic cell function. J Exp Med 2003;197:7-17.

51 Tailleux L, Schwartz O, Herrmann JL, et al. DC-SIGN is the major mycobacterium tuberculosis receptor on human dendritic cells. J Exp Med 2003; 197:121-7

52 Kanamori $Y$, Ishimaru $K$, Nanno $M$, et al. Identification of novel lymphoid tissues in murine intestinal mucosa where clusters of c-kit+ IL-7R+ Thyl+ lympho-hemopoietic progenitors develop. J Exp Med 1996;184:1449-59.

53 Hamada H, Hiroi T, Nishiyama Y, et al. Identification of multiple isolated lymphoid follicles on the antimesenteric wall of the mouse small intestine. Immunol 2002; 168:57-64

54 Moghaddami M, Cummins A, Mayrhofer G. Lymphocyte-filled villi: comparison with other lymphoid aggregations in the mucosa of the human small intestine. Gastroenterology 1998;115:1414-25.

55 Maric I, Holt PG, Perdue MH, et al. Class II MHC antiden (la)-bearing dendritic cells in the epithelium of the rat intestine. J Immunol 1996;156:1408-14.

56 Liu L, Zhang $M$, Jenkins $C$, et al. Dendritic cell heterogeneity in vivo: two functionally different dendritic cell populations in rat intestinal lymph can be distinguished by CD4 expression. J Immunol 1998;161:1146-55.

57 Huang FP, Platt N, Wykes M, et al. A discrete subpopulation of dendritic cells transports apoptotic intestinal epithelial cells to $t$ cell areas of mesenteric lymph nodes. J Exp Med 2000;191:435-44.

58 Stagg AJ, Kamm MA, Knight SC. Intestinal dendritic cells increase T cell expression of alpha4beta7 integrin. Eur J Immunol 2002;32:1445-54.

59 Pugh CW, Macpherson GG, Steer HW. Characterization of nonlymphoid cells derived from rat peripheral lymph. J Exp Med 1983;157:1758-79.

60 Holt PG, Haining S, Nelson DJ, et al. Origin and steady-state turnover of class II MHC-bearing dendritic cells in the epithelium of the conducting airways. J Immunol 1994;153:256-61.

61 Ruedl C, Koebel P, Bachmann M, et al. Anatomical origin of dendritic cells determines their life span in peripheral lymph nodes. J Immunol 2000;165:4910-16.

62 Macpherson GG, Jenkins CD, Stein MJ, et al. Endotoxin-mediated dendritic cell release from the intestine. Charaterization of released dendritic cells and TNF $\alpha$ dependence. J Immunol 1995;154:1317-22.

63 Bell SJ, Rigby R, English N, et al. Migration and maturation of human colonic dendritic cells. J Immunol 2001;166:4958-67.

64 Liu LM, Macpherson GG. Lymph-borne (veiled) dendritic cells can acquire and present intestinally administered antigens. Immunology 1991;73:281-6.

65 Kelsall BL, Strober W. Distinct populations of dendritic cells are present in the subepithelial dome and T cell regions of the murine Peyer's Patch. J Exp Med 1996; 183:237-47

66 Rescigno M, Urbano M, Valzasina B, et al. Dendritic cells express tight junction proteins and penetrate gut epithelial monolayers to sample bacteria. Nat Immunol $2001 ; 2: 361-7$

67 van Niel G, Raposo G, Candalh C, et al. Intestinal epithelial cells secrete exosome-like vesicles. Gastroenterology 2001;121:337-49.

68 Karlsson M, Lundin S, Dahlgren U, et al. "Tolerosomes" are produced by intestinal epithelial cells. Eur J Immunol 2001;31:2892-900.

69 Williamson E, Bilsborough JM, Viney JL. Regulation of mucosal dendritic cell function by receptor activator of NF-kappa B (RANK)/RANK ligand interactions: impact on tolerance induction. J Immunol 2002;169:3606-12.

70 Akbari O, DeKruyff RH, Umetsu DT. Pulmonary dendritic cells producing IL10 mediate tolerance induced by respiratory exposure to antigen. Nat Immunol 2001;2:725-31.

71 Nagata S, McKenzie C, Pender SL, et al. Human Peyer's patch T cells are sensitized to dietary antigen and display a Th cell type 1 cytokine profile. J Immunol 2000; 165:5315-21.

72 MacDonald TT, Monteleone G. IL-12 and Th1 immune responses in human Peyer's patches. Trends Immunol 2001;22:244-7.

73 Viney JL, Mowat AM, O'Malley JM, et al. Expanding dendritic cells in vivo enhances the induction of oral tolerance. J Immunol 1998;160:5815-25.

74 Williamson E, Westrich GM, Viney JL. Modulating dendritic cells to optimize mucosal immunization protocols. J Immunol 1999;163:3668-75.

75 Butcher EC, Williams M, Youngman K, et al. Lymphocyte trafficking and regional immunity. Adv Immunol 1999:72:209-53.

76 Campbell JJ, Hedrick J, Zlotnik A, et al. Chemokines and the arrest of lymphocytes rolling under flow conditions. Science 1998;279:381-4

77 Butcher EC, Picker $\amalg$. Lymphocyte homing and homeostasis. Science 1996;272:60-6.

78 Strunk D, Egger C, Leitner G, et al. A skin homing molecule defines the langerhans cell progenitor in human peripheral blood. J Exp Med 1997:185:1131-6.

79 Ito $\mathrm{T}$, Inaba $\mathrm{M}$, Inaba K, et al. A CDla+/CDI lc+ subset of human blood dendritic cells is a direct precursor of Langerhans cells. J Immunol 1999; 163:1409-19

80 Rigby RJ, Jones AM, Hart AL, et al. Identification of possible gut homing dendritic cells in perioheral blood by expression of $\beta 7$ integrin. Gastroenterology 2002;122:A153.

81 Stagg AJ, Bell SJ, Rigby RJ, et al. Treatment with anti-TNF $\alpha$ antibody reduces expression of CD40 on lamina propria dendritic cells. Gastroenterology 2000;118:A353. 
82 Vuckovic S, Florin TH, Khalil D, et al. CD40 and CD86 upregulation with divergent CMRF44 expression on blood dendritic cells in inflammatory bowel diseases. Am J Gastroenterol 2001;96:2946-56.

83 Ikeda Y, Akbar F, Matsui H, et al. Characterization of antigen-presenting dendritic cells in the peripheral blood and colonic mucosa of patients with ulcerative colitis. Eur J Gastroenterol Hepatol 2001;13:841-50.

84 te Velde AA, van Kooyk Y, Braat $\mathrm{H}$, et al. Increased expression of DCSIGN ${ }^{+} I L-12^{+} I L-18^{+}$and $C D 83^{+} I L-12^{-1 L}-18^{-}$dendritic cell populations in the colonic mucosa of patients with Crohn's disease. Eur J Immunol 2003:33:143-151.

85 Liu Z, Colpaert S, D'Haens GR, et al. Hyperexpression of CD40 ligand (CD154) in inflammatory bowel disease and its contribution to pathogenic cytokine production. J Immunol 1999;163:4049-57.

86 Waraich T, Sarsfield P, Wright DH. The accessory cell populations in ulcerative colitis: a comparison between the colon and appendix in colitis and acute appendicitis. Hum Pathol 1997;28:297-303.

87 Sarsfield P, Jones DB, Wright DH. Accesory cells in Crohn's disease of the terminal ileum. Histopathology 1996;28:213-19.

88 Pavli P, Maxwell $L$, van de Pol E, et al. Distribution of human colonic dendritic cells and macrophages. Clin Exp Immunol 1996;104:124-32.

89 Oshitani N, Sawa Y, Hara J, et al. Functional and phenotypical activation of leucocytes in inflamed human colonic mucosa. J Gastroenterol Hepatol 1997; 12:809-14.

90 Oshitani N, Kitano A, Kakazu T, et al. Functional diversity of infiltrating macrophages in inflamed human colonic mucosa ulcerative colitis. Clin Exp Pharmacol Physiol 1998;25:50-3.

91 Krajina T, Leithauser $F$, Moller $P$, et al. Colonic lamina propria dendritic cells in mice with CD4+ T cell-induced colitis. Eur J Immunol 2003;33:1073-83.

92 Leithauser F, Trobonjaca Z, Moller P, et al. Clustering of colonic lamina propria CD4(+) T cells to subepithelial dendritic cell aggregates precedes the development of colitis in a murine adoptive transfer model. Lab Invest 2001:81:1339-49.
93 Malmstrom V, Shipton D, Singh B, et al. CD134L expression on dendritic cells in the mesenteric lymph nodes drives colitis in T cell-restored SCID mice. $J$ Immunol 2001;166:6972-81.

94 Julia V, McSorley SS, Malherbe L, et al. Priming by microbial antigens from the intestinal flora determines the ability of CD4+T cells to rapidly secrete IL-4 in BALB/c mice infected with Leishmania major. J Immunol 2000; 165:5637-45.

95 Macpherson AJ, Gatto D, Sainsbury E, et al. A primitive T cell-independent mechanism of intestinal mucosal IgA responses to commensal bacteria. Science 2000;288:2222-6.

96 Khoo UY, Proctor IE, Macpherson AJ. CD4+ T cell down-regulation in human intestinal mucosa: evidence for intestinal tolerance to luminal bacterial antigens. J Immunol 1997;158:3626-34.

97 O’Boyle CJ, MacFie J, Mitchell CJ, et al. Microbiology of bacterial translocation in humans. Gut 1998:42:29-35.

98 Shiloh MU, MacMicking JD, Nicholson S, et al. Phenotype of mice and macrophages deficient in both phagocyte oxidase and inducible nitric oxide synthase. Immunity 1999;10:29-38.

99 Rigby RJ, Hart AL, Kamm MA, et al. Differential production of IL-12 and IL10 by colonic dendritic cells (DC) in response to bacterial stimuli. Gastroenterology 2002;122:A75.

100 Hart AL, Stagg AJ, Frame M et al. The role of the gut flora in health and disease, and its modification as therapy. Aliment Pharmacol Ther 2002:16:1383-93.

101 Mimura T, Rizzello F, Schreiber S, et al. Once daily high dose probiotic therapy maintains remission and improves quality of life in patients with recurrent or refractory pouchitis: a randomised placebo-controlled, double blind trial. Gastroenterology 2002;122:A81.

102 Campbell DJ, Butcher EC. Rapid acquisition of tissue-specific homing phenotypes by CD4(+) T cells activated in cutaneous or mucosal lymphoid tissues. J Exp Med 2002;195:135-41.

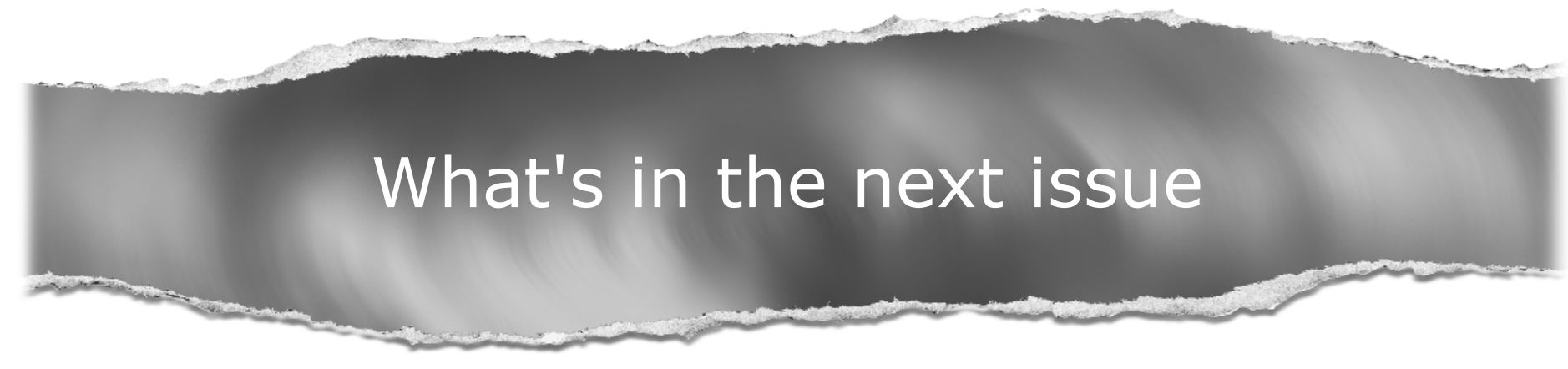

\section{Future content}

See which articles have just been accepted for publication and preview the table of contents for the next issue a month before it is published

www.gutjnl.com 